\title{
PENGARUH PIJAT OKSITOSIN TERHADAP INVOLUSI UTERUS PADA IBU POSTPARTUM
}

\author{
Vidia Safitri Aisyah*, I Gusti Ayu Mirah Widhi Sastri*, Nyimas Aziza* \\ *Dosen Jurusan Kebidanan Poltekkes Tanjungkarang
}

\begin{abstract}
Hasil presurvey peneliti yang dilakukan di salah satu BPM Bandar Lampung didapatkan data adanya peningkatan kejadian perdarahan. Masalah yang ditemukan dalam penelitian ini adalah adanya peningkatan involusi yang tidak baik dari tahun 2015 (7,5\%) dan 2016 (13,3\%). Tujuan penelitian ini adalah diketahuinya pengaruh pijat oksitosin terhadap proses involusi uterus. Jenis penelitian ini adalah Ekperimental menggunakan Quasy Eksperiment dengan penilaian posttest only control group design. Populasi penelitian ini seluruh ibu postpartum berjumlah 32 orang. Teknik sampling menggunakan purposive sampling dengan jumlah sampel 16 ibu yang diberi pijat oksitosin dan 16 ibu yang tidak diberi pijat oksitosin. Pengumpulan data menggunakan data primer dengan cara memberikan intervensi kepada responden dan mencatatnya pada lembar check list. Analisis data yang digunakan adalah univariat dan bivariat dengan Uji-t Independen. Hasil penelitian didapatkan bahwa Involusi uterus pada ibu postpartum yang diberikan pijat oksitosin memiliki rerata 3,19 jari dibawah pusat. Involusi uterus pada ibu postpartum yang tidak diberikan pijat oksitosin memiliki rerata 1,75 jari di bawah pusat. Ada pengaruh pijat oksitosin dengan proses involusi uterus. Dengan $p$ value $0,000<0,05$. Peneliti menyarankan agar pijat oksitosin dapat terus dilaksanakan dalam memberikan pelayanan postnatal kepada pasien sehingga kualitas pelayanan terhadap ibu postpartum dapat meningkat dan membantu menjadi salah satu alternatif upaya dan inovasi baru dalam mengurangi angka kematian dan perdarahan yang disebabkan oleh subinvolusi.
\end{abstract}

Kata kunci: Pijat Oksitosin, Involusi Uterus

\section{LATAR BELAKANG}

Perdarahan yang tidak terkontrol menyumbang sekitar 20-25\% kematian ibu. Perdarahan pascapartum dapat terjadi tiba-tiba dan bahkan sangat masif. Perdarahan sedang tetapi menetap dapat berlanjut selama beberapa hari atau minggu. Perdarahan pascapartum dapat terjadi dini, adalah 24 jam pertama setelah melahirkan, atau lambat. Dari 24 jam setelah melahirkan sampai hari ke 28 pascapartum. Uterus yang kuat atau berkontraksi dalam kondisi normal tidak mengalami perdarhan setelah melahirkan. Oleh karena itu, pengkajian tonus uterus yang cermat dan upaya mempertahankan kontraksi uterus melalui masase manual atau stimulasi oksitosin sesuai kebutuhan merupakan bagian terpenting perawatan pascapartum (Bobak,et al, 2005)

Pijat punggung/Pijat Oksitosin adalah suatu tindakan pemijatan tulang belakang mulai dari costa 5-6 sampai scapula akan mempercepat kerja saraf parasimpatis untuk menyampaikan perintah ke otak bagian belakang sehingga oksitosin keluar. (Suherni, 2008, Suradi, 2006, dalam Vidayanti, 2014)

Oksitosin adalah suatu hormon yang dalam kondisi normal diproduksi oleh kelenjar hipofisis posterior, yang dapat merangsang kontraksi uterus (Bobak, et al. 2005). Hormon oksitosin berguna untuk memperkuat dan mengatur kontraksi uterus, mengompresi pembuluh darah dan membantu hemostatis ibu sehingga mengurangi kejadian atonia uterus terutama pada persalinan lama. Kontraksi uterus yang kuat akan mengakibatkan proses involusi mengakibatkan proses involusi menjadi lebih bagus (Cunningham, 2006).

Dampak yang terjadi apabila tidak melakukan pijat oksitosin adalah terhambatnya proses involusi uterus dikarenakan rangsangan oksitosin yang sedikit sehingga kontraksi uterus tidak adekuat dan dapat menyebabkan subinvolusi uterus yang pada peristiwa ini 
lokhia bertambah banyak dan tidak jarang terdapat pula perdarahan (Sarwono, 2014: 655). Perdarahan merupakan komplikasi dari persalinan yang merupakan penyebab utama morbiditas dan mortalitas maternal (Anonim, 2005 dalam jurnal Hamranani).

Menurut penelitian Stanton, menyatakan upaya penanganan perdarahan postpartum adalah dengan pemberian oksitosin,dimana oksitosin mempunyai peranan penting dalam merangsang kontraksi otot polos uterus sehingga perdarahan dapat teratasi. Hasil dari penelitiannya menunjukkan rata-rata jumlah perdarahan setelah plasenta lahir diberikan injeksi oksitosin lebih sedikit dibandingkan tanpa diberikan injeksi oksitosin. Oksitosin dapat diperoleh dengan berbagai cara baik melalui oral, intra-nasal, intra-muscular, maupun dengan pemijatan yang merangsang keluarnya hormon oksitosin. Sebagaimana ditulis Lun, et al (2002)

\section{METODE}

Penelitian ini merupakan penelitian Quasy Eksperiment dengan pendekatan Posttest Only Control Group Design yang dilakukan pada 2 kelompok ibu postpartum normal di BPM Nurmala Dewi Rajabasa Bandar Lampung bulan Februari-April 2017. Satu kelompok diberi pijat oksitosin sebagai kelompok intervensi dan satu kelompok tidak diberi pijat oksitosin sebagai kelompok kontrol. Kedua kelompok dilakukan asuhan persalinan normal dan inisiasi menyusu dini (IMD).

Responden penelitian ini adalah ibu postpartum pervaginam dan normal. Sebelum dilakukan tindakan dilakukan informed choice untuk mendapatkan informed consent pada setiap responden. Jika dalam perjalanan ditemukan ibu postpartum yang mengkonsumsi rumput fatima dan atau ibu postpartum yang mengalami perdarahan maka reponden dikeluarkan.

Jumlah sampel dalam penelitian ini ditentukan dengan rumus besar sampel pada rancangan acak sederhana eksperimental diperoleh besar sampel sebanyak 16 orang per kelompok.

Analisis statistik yang digunakan dalam penelitian ini adalah uji normalitas dengan Komolgof-Smirnov, uji homogenitas antar kelompok menggunakan uji Levene. Data yang berdistribusi normal dan homogen dianalisis dengan menggunakan uji t tidak berpasangan. Data kategorik dianalisis dengan menggunakan chi kuadrat. Seluruh analisis data diproses dengan program komputer dengan tingkat signifikansi $\mathrm{p}<0,05$.

\section{HASIL}

\section{Analisis Univariat}

Tabel 1: Rerata Involusi Uterus pada Responden yang Diberi dan Tidak Diberi Pijat Oksitosin

\begin{tabular}{|c|c|c|c|}
\hline $\begin{array}{c}\text { Pijat } \\
\text { Oksitosin }\end{array}$ & Mean SD & $\begin{array}{l}\text { Min- } \\
\text { Maks }\end{array}$ & $95 \% \mathrm{CI}$ \\
\hline iberi & $3,190,655$ & $2-4$ & \\
\hline idak D & $1,750,577$ & $1-3$ & 1.44 \\
\hline
\end{tabular}

Dari tabel analisis di atas didapatkan rerata involusi uterus ibu postpartum yang diberi pijat oksitosin adalah 3,19 (95\% CI: $2,84-3,54)$, dengan standar deviasi 0,655. Involusi uterus pada ibu yang diberi pijat oksitosin minimum 2 jari di bawah pusat dan maksimum 4 jari di bawah pusat. Dari hasil estimasi interval dapat disimpulkan bahwa 95\% diyakini rerata involusi uterus ibu postpartum yang diberi pijat oksitosin adalah diantara 2,84 sampai dengan 3,54. Sedangkan untuk rerata involusi uterus ibu post partum yang tidak diberi pijat oksitosin adalah 1,75 (95\% CI: 1,44 2,06), dengan standar deviasi 0,577. Involusi uterus pada ibu yang tidak diberi pijat oksitosin minimum 1 jari dibawah pusat dan maksimum 4 jari dibawah pusat. Dari hasil estimasi interval dapat disimpulkan bahwa 95\% diyakini rerata involusi uterus ibu postpartum yang tidak diberi pijat oksitosin adalah diantara 1,44 sampai dengan 2,06. 
Berdasarkan data yang diperoleh dari perhitungan hasil uji Komolgof-Smirnov dapat disimpulkan bahwa data rata-rata berdistribusi normal karena memiliki nilai $p>0,05$. Hasil involusi uterus kelompok eksperimen memiliki nilai $\mathrm{p}=0,239$ dan hasil involusi uterus kelompok kontrol memiliki nilai $p=0,587$. Sehingga dapat disimpulkan bahwa data berdistribusi normal.

Berdasarkan analisis Levene, dapat dilihat homogenitas signifikan dengan nilai $\mathrm{p}=0,758$ yang berarti $\mathrm{p}>0,05$, sehingga data dapat disimpulkan homogen atau memiliki varian yang sama. Karena data normal dan homogen maka analisis yang digunakan adalah data $\mathrm{Uji} \mathrm{t}$ tidak berpasangan.

\section{Analisis Bivariat}

Tabel 2: Pengaruh Pijat Oksitosin terhadap Involusi Uterus Ibu Postpartum

\begin{tabular}{llll}
\hline \multicolumn{1}{c}{ Variabel } & Mean SD SE $\begin{array}{c}p \\
\text { value }\end{array}$ & $\mathrm{n}$ \\
\hline $\begin{array}{l}\text { Diberi } \\
\text { Pijat Oksitosin }\end{array}$ & 3,19 & $0,6550,164$ & 16 \\
\hline $\begin{array}{llll}\text { Tidak Diberi } \\
\text { Pijat Oksitosin }\end{array}$ & 1,75 & $0,5770,144$ & 16 \\
\hline
\end{tabular}

Dari data tersebut dapat terlihat bahwa pada kelompok eksperimen (ibu postpartum yang diberi pijat oksitosin) dengan jumlah responden $16 \mathrm{ibu}$ postpartum memiliki mean (rata-rata) 3,19. Sedangkan pada kelompok kontrol (ibu postpartum yang tidak diberi pijat oksitosin) memiliki rata-rata 1,75 dengan jumlah responden $16 \mathrm{ibu}$ postpartum. Hasil uji statistik dengan Uji-t Independen didapatkan nilai $P$ value $0,000<0,05$ sehingga Ho ditolak. Dari hasil analisa Uji-t Independen maka dapat diambil kesimpulan bahwa ada pengaruh pijat oksitosin terhadap involusi uterus ibu postpartum. Berdasarkan analisis data tersebut dapat dikatakan bahwa ada perbedaan involusi uterus antara ibu yang diberi pijat oksitosin dengan ibu yang tidak diberi pijat oksitosin. Sehingga dapat disimpulkan bahwa ada pengaruh pijat oksitosin terhadap involusi uterus ibu postpartum. Dapat disimpulkan pula pengaruh pijat oksitosin terhadap involusi uterus ibu postpartum dalam kategori tinggi $(81 \%)$.

\section{PEMBAHASAN}

Hasil penelitian ini menjelasakan bahwa rerata involusi uterus ibu postpartum yang diberi pijat oksitosin adalah 3,19 (95\% CI: 2.84 - 3.54), dengan standar deviasi 0,655 . Involusi uterus pada ibu yang diberi pijat oksitosin minimum 2 jari dibawah pusat dan maksimum 4 jari dibawah pusat. Hal ini berarti kelompok responden yang diberi pijat oksitosin mengalami involusi uterus lebih cepat dibandingkan kelompok responden yang tidak diberi pijat oksitosin.

Penelitian ini sejalan dengan teori yang ada bahwa pada tahap ketiga persalinan, uterus berada di garis tengah, kira-kira $2 \mathrm{~cm}$ di bawah umbilikus dengan bagian fundus bersandar pada promontorium sakralis. Dalam waktu 12 jam, tinggi fundus uterus mencapai kurang lebih $1 \mathrm{~cm}$ diatas umbilikus. Dalam beberapa hari kemudian, perubahan involusi uterus berlangsung dengan cepat. Fundus turun kira-kira $1-2 \mathrm{~cm}$ setiap 24 jam. (Dewi \& Sunarsih, 2011). Pijat Oksitosin adalah suatu tindakan pemijatan tulang belakang mulai dari cervikal 7 sampai scapula akan mempercepat kerja saraf parasimpatis untuk menyampaikan perintah ke otak bagian belakang sehingga oksitosin keluar (Suherni, 2008; Suradi, 2006 dalam jurnal Hamranani). Hormon oksitosin berguna untuk memperkuat dan mengatur kontraksi uterus, mengompresi pembuluh darah dan membantu hemostasis ibu. Kontraksi uterus yang kuat akan mengakibatkan proses involusi menjadi lebih bagus (Cunningham, 2006).

Hasil penelitian yang dilakukan oleh Fauziah H. Wada dan Alfaina Wahyuni di Fakultas Ilmu keperawatan Universitas Muhammadiyah Yogyakarta tahun 2014 menunjukkan bahwa terdapat penurunan 
TFU yang bermakna pada kelompok intervensi $(\mathrm{p}=0,000)$, sedangkan pada kelompok kontrol tidak bermakna $(\mathrm{p}=0,865)$.

Berdasarkan teori dan hasil penelitian diatas, menurut peneliti involusi uterus yang terjadi pada ibu postpartum yang diberi pijat oksitosin cukup baik, karena pada umumnya involusi uterus untuk hari ke-2 adalah $\geq 2$ jari dibawah pusat. Dengan memberikan pijat oksitosin dapat memperkuat dan mengatur kontraksi uterus dengan baik sehingga involusi uterus dapat menjadi lebih baik.

Diharapkan dengan pijat oksitosin bidan dapat meningkatkan kualitas terhadap pelayanan ibu postpartum sehingga dapat membantu menjadi salah satu alternatif upaya dan inovasi baru dalam mengurangi angka perdarahan yang disebabkan oleh subinvolusi.

Dari hasil penelitian menunjukkan bahwa ibu postpartum yang tidak diberi pijat oksitosin memiliki rerata involusi uterus ibu post partum yang tidak diberi pijat oksitosin adalah 1,75 (95\% CI: 1.44 2.06), dengan standar deviasi 0,577. Involusi uterus pada ibu yang tidak diberi pijat oksitosin minimum 1 jari dibawah pusat dan maksimum 3 jari dibawah pusat. Sehingga involusi uterus pada ibu yang tidak diberi pijat oksitosin berjalan lebih lambat daripada yang diberi pijat oksitosin.

Menurut Prawirohardjo (2014) dampak yang terjadi apabila tidak melakukan pijat oksitosin adalah terhambatnya proses involusi uterus dikarenakan rangsangan oksitosin yang sedikit sehingga kontraksi uterus tidak adekuat dan dapat menyebabkan subinvolusi uterus yang pada peristiwa ini lokhia bertambah banyak dan tidak jarang terdapat pula perdarahan.

Hasil penelitian yang dilakukan oleh Hamranani tentang pengaruh pijat oksitosin terhadap involusi uterus pada ibu post partum di dengan persalinan lama di rumah sakit wilayah kabupaten klaten menunjukkan hasil pengamatan hari kedua responden yang mengalami involusi uterus tidak normal sebanyak 35 orang $(42,7 \%)$ yang terdiri dari kelompok tanpa pijat oksitosin 32 orang (39\%) dan 3 orang dari kelompok dengan pijat oksitosin.

Berdasarkan teori dan hasil pengamatan menurut peneliti pada ibu yang tidak dilakukan pijat oksitosin memiliki proses involusi yang lambat dibandingkan dengan yang dipijat oksitosin karen oksitosin yang disuntikkan pada ibu pada saat kala III mempunyai lama kerja 2-3 jam setelah disuntiikan sehingga setelah 3 jam apabila ibu tidak diberi rangsangan oksitosin maka kontraksi uterus akan menurun sehingga involusi uterus lebih lambat dibandingkan dengan ibu yang diberikan pijat oksitosin.

Berdasarkan analisis pengaruh pijat oksitosin terhadap involusi uterus diketahui bahwa dari 16 responden yang diberi pijat oksitosin terdapat 2 orang dengan TFU 2 jari dibawah pusat, 9 orang dengan TFU 3 jari dibawah pusat, dan 5 orang dengan TFU 4 jari dibawah pusat. Sedangkan untuk 16 responden yang tidak diberi pijat oksitosin terdapat 5 orang dengan TFU 1 jari bawah pusat, 10 orang dengn TFU 2 jari bawah pusat, dan 1 orang dengan TFU 3 jari bawah pusat.

Hasil uji statistik menggunakan $t$-test Independent diperoleh nilai $\mathrm{p}$ value < nilai $\alpha$ yaitu $0,000<0,05$ artinya Ho ditolak dengan demikian dapat disimpulkan bahwa ada pengaruh yang signifikan pijat oksitosin terhadap involusi uterus. Perbedaan rerata involusi uterus ibu postpartum yang diberi pijat oksitosin adalah 1,44 yang artinya pada ibu postpartum tidak diberi pijat oksitosin mempunyai rerata involusi uterus yang lebih lambat.

Hasil penelitian ini sejalan dengan hasil penelitian Faizatul Ummah (2014) tentang Pijat Oksitosin Untuk Mempercepat Pengeluaran Asi Pada Ibu Pasca Salin Normal Di Dusun Sono Desa Ketanen Kecamatan Panceng Gresik dengan hasil penelitian menunjukkan pengeluaran ASI pada kelompok intervensi pijat oksitosin lebih cepat $($ mean $=6.2143)$ daripada kelompok kontrol (mean = 8.9286). Hasil uji independent sample didapatkan $\mathrm{p}$ value $=0,000 \quad(<0,005)$ artinya ada pengaruh pijat oksitosin 
terhadap pengeluaran ASI pada ibu pasca salin normal di Dusun Sono Desa Ketanen Kecamatan Panceng Gresik, sehingga dapat disimpulkan bahwa pijat oksitosin dapat mempercepat pengeluaran ASI.

Berdasarkan teori dan hasil penelitian diatas menurut peneliti ada pengaruh pijat oksitosin terhadap involusi uterus, karena dengan melakukan pijat oksitosin dapat merangsang hormon oksitosin yang menimbulkan kontraksi uterus sehingga involusi uterus dapat berjalan dengan lebih baik. Keberhasilan pelaksanaan pijat oksitosin didukung oleh kondisi ibu yang baik, kesadaran dan motivasi yang tinggi dari responden untuk melakukan pemijatan oksitosin. Peran serta tenaga kesehatan juga dibutuhan untuk memberikan pendidikan kesehatan pada ibu post partum terutama tentang involusi uterus dan pijat oksitosin.

\section{KESIMPULAN}

Penelitian ini menyimpulkan bahwa ada pengaruh pijat oksitosin terhadap involusi uterus ibu postpartum dapat diuraikan sebagai berikut: Involusi uterus pada ibu postpartum yang diberikan pijat oksitosin memiliki rerata 3,19 jari di bawah pusat. Involusi uterus pada ibu postpartum yang tidak diberikan pijat oksitosin memiliki rerata 1,75 jari di bawah pusat. Ada pengaruh pijat oksitosin dengan proses involusi uterus pada ibu postpartum. Dengan $p$ value $0,000<0,05$.

Selanjutnya penulis menyarankan kepada tenaga kesehatan khususnya kepada tenaga kesehatan yang bekerja di fasilitas kesehatan yang memberikan pelayanan postnatal, untuk memberikan pijat oksitosin kepada ibu postpartum sebagai salah satu alternatif upaya dan inovasi baru dalam mengurangi angka kematian ibu yang disebabkan oleh perdarahan postpartum

\section{DAFTAR PUSTAKA}

Bobak, lowdermilk, Jensen. 2005. Buku Ajar Keperawatan Maternitas Edisi 4. Jakarta: EGC.

Hamranani ST. 2010. Pengaruh Pijat Oksitosin terhadap Involusi Uterus pada Ibu Postpartum dengan Persalinan Lama di Rumah Sakit Wilayah Kabupaten Klaten. Jakarta: FIK Universitas Indonesia.

Lia Dewi, Tri Sunarsih. 2011. Asuhan Kebidanan pada Ibu Nifas. Jakarta: Salemba Medika. 198 halaman.

Prawirohardjo, Sarwono. 2014. Ilmu Kebidanan. Jakarta: PT Bina Pustaka Sarwono Prawirohardjo. 982 halaman.

Ummah, Faizatul. 2014. Pijat Oksitosin Mempercepat Pengeluaran ASI pada Ibu Pasca Salin Normal di Dusun Sono Desa Ketanen Kecamatan Panceng Gresik. Surya. http/stikesmuhla.ac.id/wpcontent/upload. Diakses pada 13 januari 2017.

Wada. 2014. Pengaruh Pijat Oksitosin terhadap Involusi Uterus pada Ibu Postpartum Primigravida di RSUD Panembahan Senopati Bantul Yogyakarta. Skripsi Sarjana Fakultas Kedokteran dan Ilmu Kesehatan Universitas Muhamadiyah Yogyakarta. 